\title{
Lifestyle characteristics influencing hypertension in middle-age to old people: comparison of two populations
}

\author{
Selma Cvijetic ${ }^{1}{ }^{1}$, Josipa Kern $\mathbb{1}^{2}$, Silvije Vuletić $\circledast^{2}$, Jasminka Z. Ilich $\oplus^{3}$ \\ 'Institute for Medical Research and Occupational Health, Zagreb, Croatia \\ ${ }^{2}$ Andrija Štampar Teaching Institute of Public Health, Zagreb, Croatia \\ ${ }^{3}$ Florida State University, Tallahassee, United Stated
}

\begin{abstract}
Background: Hypertension is a significant global public health problem and the data suggest a wide health disparity in hypertension prevalence worldwide. Our objective was to assess some epidemiological determinants in individuals $\geq 50$ years influencing blood pressure/hypertension in United States and Croatia and derive some meaningful conclusions and recommendations.

Material and methods: We used the American National Health and Nutrition Examination Survey (NHANES) $(\mathrm{n}=1,556 ; 48.9 \%$ women) and the Croatian Adult Health Cohort Study (CroHort) ( $\mathrm{n}=2,182 ; 66 \%$ women), both taken in 2008. The health indicators compared were anthropometries, blood pressure, socioeconomic and marital status, education and lifestyle, including physical activity, alcohol and coffee consumption, smoking and presence of dyslipidemia and diabetes.

Results: Prevalence of hypertension based either on medication use or blood pressure values was significantly higher in Croatian men and women compared to American (all $\mathrm{p}<0.001$ ). Waist circumference was the main positive predictor and education a negative predictor for blood pressure in CroHort; significance was not reached in NHANES, although the trends were similar. Taking medications for diabetes decreased the odds for hypertension in NHANES, while taking medications for both diabetes and dyslipidemia decreased the odds in CroHort.

Conclusions: Croatian people older than 50 years have higher prevalence of hypertension compared to their counterparts in the U.S. The difference in the prevalence of hypertension in two populations cannot be explained by different prevalence of risk factors examined, except education level. Higher prevalence of hypertension diagnosed by medication use indicates a relatively good control of the disease in both populations.

Key words: blood pressure; hypertension; NHANES; Croatian Adult Health Cohort Study (CroHort); alcohol and coffee consumption; smoking
\end{abstract}

\section{Introduction}

Long-term higher blood pressure is a major risk factor for coronary artery disease, stroke and heart failure, which are the main causes of death in majority of developed countries [1]. Even in countries with good health care, an unhealthy lifestyle increases the prevalence of hypertension and overall morbidity [2-4]. Recent epidemiological data showed higher prevalence of hypertension in Croatian women com-

Address for correspondence: Selma Cvijetic,

Institute for Medical Research and Occupational Health, Ksaverska cesta 2, Zagreb, Croatia; e-mail: cvijetic@imi.hr

V M Copyright (C) 2020 Via Medica, ISSN 2449-6170 
pared to United States women, which was surprising since the latter also included the African American women, known for having disproportionally higher blood pressure and other cardiovascular risk factors compared to their white counterparts [5-7]. Croatia is a European Union country in South-East Europe and is classified as high-income country [8]. Croatian population is ethnically homogenous (Caucasians) and in that context, Croatia could be compared with the United States Caucasian population.

The leading cause of death in the United States in 2017 was heart diseases at the rate of $23.0 \%$, as a percentage of total deaths, which was similar as in 2008 when the rate was $25.0 \%$ [9]. When the rate for cerebrovascular diseases is added to heart diseases, then the total rate was $29.1 \%$ in 2017 and $30.4 \%$ in 2008. In Croatia, the leading cause of death was circulatory diseases, which comprises both heart and cerebrovascular diseases with the percentage of total deaths of $44.0 \%$ in 2017 and $50.3 \%$ in 2008 [10].

Although there are studies investigating the effect of demographic and lifestyle factors on hypertension, there is a lack of studies comparing directly two large populations. The objective of this study was to assess some epidemiological characteristics influencing blood pressure in general and specifically hypertension of middle age to older Croatian citizens and compare them with sex and age-matched Caucasian Americans. Based on the assumption that social, economic conditions and lifestyle differ between two countries, we investigated which of them were most important to describe the possible differences in prevalence of hypertension in two countries. We took into account anthropometry, socioeconomic and marital status, education and lifestyle habits including physical activity, alcohol and caffeine consumption, smoking, and the presence of dyslipidemia and diabetes.

\section{Material and methods}

\section{Study participants and variables collected}

For the Croatian sample, the database from the Croatian Adult Health Cohort study (CroHort), one of the largest health assessments in Croatia, was utilized [11]. Briefly, the CroHort started in 2003 and was repeated in 2008 with the aim to provide comprehensive data about health of Croatian population as part of a project for prevention of cardio-vascular diseases. CroHort focused on health status, use of health services and health determinants with emphasis on cardio-vascular diseases risks. All surveys were carried out by public health nurses who visited participants throughout the country. In 2003, a total number of 9,070 adults were contacted and interviewed, with the response rate of $84.3 \%$. Of those, 3,229 (35.6\%) were revisited and resurveyed in 2008. For the purpose of this study, only participants $\geq 50$ years from 2008 assessment were evaluated and the total of $\mathrm{n}=$ 2,182 (66\% women) were analyzed.

For the American sample, the comparable database from the National Health and Nutrition Examination Survey (NHANES) was used. The objectives of NHANES were to collect health-related data and dietary intake of the United States population and their change over time [12]. For the purpose of this study, data from 2007-2008 "Continuous" survey were used and included Caucasian participants over the age of $\geq 50$ years, total $n=1,556(48.9 \%$ women), and compared with CroHort participants. Response rates in the NHANES 2007-2008 was $75.4 \%$. Data collected from these two data sets were:

1. Physical measurements:

- height and weight: body mass index (BMI) was calculated according to the formula:

\section{Weight $(\mathrm{kg}) /$ height $(\mathrm{m})^{2}$}

- waist circumference,

- blood pressure,

- heart rate.

2. Socio-demographic characteristics:

- number of person in the household,

- annual household income, adjusted for the household spending, which is the amount of final consumption expenditure made by resident households to meet their everyday needs, such as: food, clothing, housing (rent), energy, transport, durable goods (notably, cars), health costs, leisure, and miscellaneous services. It is typically around $60 \%$ of gross domestic product (GDP) [13]. In 2008, the household spending was $58.13 \%$ of GDP in Croatia and $67.16 \%$ of GDP in the United States [14]. Correction is made by increasing the annual income in Croatia for the difference in household spending between two countries, which is $9.03 \%$.

3. Self-reported chronic disease and medication use for hypertension, diabetes and hyperlipidemia.

4. Lifestyle:

- smoking (smoking index was calculated by number of cigarettes smoked per day multiplied by number of smoking years);

- number of alcoholic drinks per day (high alcohol consumption was defined as having a binge of heavy drinking at least once a week).

The CroHort study was approved by the Zagreb University School of Medicine Ethics Committee. 
Institutional Review Board (IRB) approval and documented consent was obtained from NHANES participants.

\section{Statistical analysis}

Statistical analysis was performed using the Statistica software (version 13, Tulsa, OK). Distributions of outcome variables were examined by KolmogorovSmirnov test. Descriptive statistics was calculated for all variables and means and standard deviations are reported. Two-sample t-tests were used to determine differences between the two populations for continuous variables, while the chi-square tests were used for categorical variables. For variables with more than three categories (e.g. annual income, education and marital status) differences among categories were tested with ANOVA. Association between hypertension (defined as taking hypertension medications) was examined with logistic regression, separately for two cohorts, using Rosenbrock and quasi-Newton pattern search method. For all tests, $\mathrm{p}<0.05$ was considered significant.

\section{Results}

Participants from NHANES were significantly older than participants from CroHort (Tab. 1). All anthropometric measurements, except height, were significantly higher in male participants from NHANES compared to those from CroHort. On the contrary, female CroHort participants had significantly higher height, weight and body mass index compared to those from NHANES. According to body mass index, significantly more men from NHANES were overweight compared to men from CroHort, while significantly more women from CroHort were obese. Systolic and diastolic pressures were significantly higher in CroHort compared to NHANES participants ( $\mathrm{p}<0.001$ for men and women).

Number of household members was lower in NHANES men and higher in women, compared to respective CroHort participants (Tab. 2). Regarding the adjusted income, more American men were in the two highest income categories, while more Croatian women were in some of the middle and top income categories, although the percentage for the latter was low (Tab. 2). Considering the marital status, more Americans of both sexes were divorced, while more Croatians were widowed. Considering education level, more American men had less than primary school, but also more men had higher education level (college graduate or above) than Croatians. More Croatian women had less than primary school and more American women had higher education level. Significantly, more men from NHANES were physically active compared to men from CroHort, while no significant difference in physical activity was found between women from two cohorts (Tab. 2).

Table 1. Age, anthropometric characteristics and blood pressure of two cohorts

\begin{tabular}{|c|c|c|c|c|c|c|}
\hline \multirow{2}{*}{ Variables } & \multicolumn{2}{|c|}{$\begin{array}{c}\text { Men } \\
\text { Mean } \pm \text { SD or N (\%) }\end{array}$} & \multirow{2}{*}{ p } & \multicolumn{2}{|c|}{$\begin{array}{c}\text { Women } \\
\text { Mean } \pm \text { SD or } N(\%)\end{array}$} & \multirow{2}{*}{ p } \\
\hline & $\begin{array}{l}\text { NHANES } \\
(\mathrm{n}=794)\end{array}$ & $\begin{array}{l}\text { CroHort } \\
(\mathrm{n}=739)\end{array}$ & & $\begin{array}{l}\text { NHANES } \\
(\mathrm{n}=762)\end{array}$ & $\begin{array}{l}\text { CroHort } \\
(n=1443)\end{array}$ & \\
\hline Age [yrs] & $67.4 \pm 10.0$ & $65.8 \pm 8.8$ & 0.001 & $67.8 \pm 9.7$ & $65.3 \pm 8.6$ & $<0.001$ \\
\hline Height [cm] & $174.6 \pm 6.9$ & $174.3 \pm 8.5$ & NS & $160.7 \pm 6.2$ & $162.7 \pm 6.8$ & $<0.001$ \\
\hline Weight [kg] & $88.7 \pm 18.7$ & $84.4 \pm 14.6$ & $<0.001$ & $73.3 \pm 16.8$ & $76.7 \pm 13.8$ & $<0.001$ \\
\hline BMI $\left[\mathrm{kg} / \mathrm{m}^{2}\right]$ & $29.0 \pm 5.4$ & $27.7 \pm 4.3$ & $<0.001$ & $28.3 \pm 6.1$ & $28.9 \pm 5.1$ & 0.012 \\
\hline $\begin{array}{l}\text { Waist } \\
\text { circumference }[\mathrm{cm}]\end{array}$ & $106.6 \pm 15.1$ & $102.6 \pm 13.9$ & $<0.001$ & $96.7 \pm 16.5$ & $97.8 \pm 13.9$ & NS \\
\hline $\begin{array}{l}\text { Overweight } \\
(\mathrm{BMI}>25)\end{array}$ & $331(41.6)$ & $233(31.5)$ & $<0.001$ & $331(43.4)$ & $581(40.2)$ & NS \\
\hline $\begin{array}{l}\text { Obesity } \\
(\mathrm{BMI}>30)\end{array}$ & $275(34.6)$ & $243(32.8)$ & NS & $201(26.3)$ & $535(37.0)$ & $<0.001$ \\
\hline $\begin{array}{l}\text { Systolic blood pressure } \\
{[\mathrm{mm} \mathrm{Hg}]}\end{array}$ & $132.4 \pm 19.5$ & $139.8 \pm 19.5$ & $<0.001$ & $134.8 \pm 21.6$ & $138.8 \pm 20.4$ & $<0.001$ \\
\hline $\begin{array}{l}\text { Diastolic blood pressure } \\
\text { [mm Hg] }\end{array}$ & $70.8 \pm 10.2$ & $82.0 \pm 10.2$ & $<0.001$ & $68.5 \pm 10.3$ & $81.6 \pm 10.4$ & $<0.001$ \\
\hline
\end{tabular}

$\mathrm{BMI}$ - body mass index; NS — non significant; SD — standard deviation. Differences were tested with $\mathrm{t}$ test and chi-square test 
Table 2. Demographic characteristics of two cohorts

\begin{tabular}{|c|c|c|c|c|c|c|}
\hline \multirow{2}{*}{ Variables } & \multicolumn{2}{|c|}{$\begin{array}{c}\text { Men } \\
\text { Mean (SD) or N (\%) }\end{array}$} & \multirow{2}{*}{$\mathbf{p}$} & \multicolumn{2}{|c|}{$\begin{array}{c}\text { Women } \\
\text { Mean (SD) or N (\%) }\end{array}$} & \multirow{2}{*}{$\mathbf{p}$} \\
\hline & $\begin{array}{l}\text { NHANES } \\
(\mathrm{n}=794)\end{array}$ & $\begin{array}{c}\text { CroHort } \\
(\mathrm{n}=739)\end{array}$ & & $\begin{array}{l}\text { NHANES } \\
(\mathrm{n}=762)\end{array}$ & $\begin{array}{c}\text { CroHort } \\
(n=1443)\end{array}$ & \\
\hline Household members & $2.2 \pm 1.0$ & $2.6 \pm 1.4$ & $<0.001$ & $3.4 \pm 1.9$ & $2.5 \pm 1.5$ & $<0.001$ \\
\hline $\begin{array}{l}\text { Annual income (USD) } \\
<5,000 \\
5,000-19,999 \\
20,000-44,999 \\
45,000-74,999 \\
75,000-99,999 \\
\geq 100,000\end{array}$ & $\begin{array}{c}5(0.6) \\
145(18.2) \\
264(33.2) \\
124(13.4) \\
63(15.6) \\
131(16.4)\end{array}$ & $\begin{array}{c}10(1.3) \\
177(23.9) \\
252(34.1) \\
126(17.0) \\
48(6.5) \\
1.1(20.8)\end{array}$ & $<0.001^{1}$ & $\begin{array}{c}(n=665)^{*} \\
15(0.1) \\
176(26.4) \\
301(45.2) \\
69(10.3) \\
26(3.9) \\
18(2.7)\end{array}$ & $\begin{array}{c}(n=1303)^{*} \\
48(3.6) \\
451(34.6) \\
479(36.7) \\
129(9.9) \\
25(1.9) \\
23(1.7)\end{array}$ & $<0.001^{1}$ \\
\hline $\begin{array}{l}\text { Marital status } \\
\text { Married } \\
\text { Single } \\
\text { Divorced } \\
\text { Widowed }\end{array}$ & $\begin{array}{c}570(71.8) \\
52(6.5) \\
97(12.3) \\
75(9.4)\end{array}$ & $\begin{array}{c}563(76.2) \\
53(7.2) \\
29(3.9) \\
94(12.7)\end{array}$ & $<0.001^{1}$ & $\begin{array}{c}400(52.5) \\
27(3.5) \\
121(15.9) \\
214(28.1)\end{array}$ & $\begin{array}{c}748(52.1) \\
57(3.9) \\
82(5.7) \\
550(38.3)\end{array}$ & $<0.001^{1}$ \\
\hline $\begin{array}{l}\text { Education } \\
\text { Less than primary school } \\
\text { Primary school } \\
\text { High school } \\
\text { Some college degree } \\
\text { College or above }\end{array}$ & $\begin{array}{c}94(11.8) \\
93(11.7) \\
212(26.7) \\
196(24.7) \\
199(25.1)\end{array}$ & $\begin{array}{l}(=731)^{*} \\
69(9.4) \\
164(22.4) \\
369(50.5) \\
68(9.3) \\
60(8.4)\end{array}$ & $<0.001^{1}$ & $\begin{array}{c}(n=762)^{*} \\
56(7.3) \\
106(13.9) \\
248(32.6) \\
206(27.1) \\
146(19.1)\end{array}$ & $\begin{array}{c}(n=1425)^{*} \\
286(20.0) \\
460(32.3) \\
515(36.2) \\
91(6.4) \\
73(5.1)\end{array}$ & $<0.001^{1}$ \\
\hline $\begin{array}{l}\text { Physical activity } \\
\text { None } \\
\text { Occupational/recreation } \\
\text { Both }\end{array}$ & $\begin{array}{c}400(50.4) \\
319(40.2) \\
75(9.4)\end{array}$ & $\begin{array}{c}467(62.1) \\
233(32.4) \\
27(3.5)\end{array}$ & $\begin{array}{c}0.001 \\
0.001 \\
<0.001\end{array}$ & $\begin{array}{c}467(61.3) \\
271(35.6) \\
23(3.1)\end{array}$ & $\begin{array}{c}928(64.9) \\
429(31.6) \\
44(3.5)\end{array}$ & $\begin{array}{l}\text { NS } \\
\text { NS } \\
\text { NS }\end{array}$ \\
\hline
\end{tabular}

NS — non significant; SD — standard deviation; 'Differences between all categories were tested with ANOVA. Differences between means of household members and physical activity parameters were tested with $t$ test. *Number of participants with available data when different from total $n$

Significantly more CroHort than NHANES participants were using medications for hypertension. Accordingly, the prevalence of hypertension in CroHort was significantly higher than that in NHANES participants ( $p<0.027$ for men and $p<0.019$ for women) (Tab. 3). The prevalence of hypertension based on blood pressure values $(\geq 140 \mathrm{~mm} \mathrm{Hg}$ of systolic pressure and $\geq 90 \mathrm{~mm} \mathrm{Hg}$ of diastolic pressure) was: $34.3 \%$ in men and $40.1 \%$ in women from NHANES and $45.9 \%$ in men and $46.3 \%$ in women from CroHort (not presented). These prevalence rates were significantly lower compared to those based on taking medication for hypertension ( $\mathrm{p}<$ 0.001 for both studies). Among participants with blood pressure $\geq 140 / 90 \mathrm{~mm} \mathrm{Hg}, 62.6 \%$ of men and $66.8 \%$ of women from NHANES and also $71.4 \%$ of men and $79.9 \%$ of women from CroHort were taking medications for hypertension $(\mathrm{p}<0.001$ for both studies). There was no significant difference in taking medication for hyperlipidemia and diabetes between NHANES and CroHort participants (Tab. 3). However, significantly more men from NHANES were taking medications for all three diseases compared to men from CroHort, while that difference was not significant in women (not presented).

The prevalence of alcohol consumption in men was $54.7 \%$ in NHANES and $61.4 \%$ in CroHort $(\mathrm{p}=0.043)$. The corresponding prevalence in women was $43.9 \%$ and $31.8 \%(\mathrm{p}<0.001)$.

Participants from NHANES consumed significantly higher number of alcoholic drinks per day than Croatians (Tab. 3). Average prevalence of binge drinking was significantly higher in NHANES (6.6\% men, $0.9 \%$ women) compared to CroHort $(0.8 \%$ men and women). Notably, both systolic and diastolic pressure was significantly higher in women from NHANES who were binge drinkers compared to those who were not $(\mathrm{p}=0.046)$ (not presented). There was no significant difference in number of cigarettes per day among the smokers between two groups, but significantly more NHANES participants smoked longer than 5 years compared to CroHort participants (Tab. 3). No significant difference in caffeine intake was found between participants from NHANES and CroHort. There was no difference in mean blood pressure between participants 
Table 3. Medications use, drinking and smoking parameters and caffeine intake in two cohorts

\begin{tabular}{|c|c|c|c|c|c|c|}
\hline \multirow{2}{*}{ Variables } & \multicolumn{2}{|c|}{$\begin{array}{c}\text { Men } \\
\text { Mean } \pm \text { SD or N (\%) }\end{array}$} & \multirow{2}{*}{$\mathbf{p}$} & \multicolumn{2}{|c|}{$\begin{array}{c}\text { Women } \\
\text { Mean } \pm \text { SD or } \mathbf{N}(\%)\end{array}$} & \multirow{2}{*}{$\mathbf{p}$} \\
\hline & $\begin{array}{l}\text { NHANES } \\
(\mathrm{n}=794)\end{array}$ & $\begin{array}{l}\text { CroHort } \\
(\mathrm{n}=739)\end{array}$ & & $\begin{array}{l}\text { NHANES } \\
(\mathrm{n}=762)\end{array}$ & $\begin{array}{l}\text { CroHort } \\
(n=1443)\end{array}$ & \\
\hline Hypertension medications & $323(40.7)$ & $342(46.3)$ & 0.027 & $384(50.5)$ & $803(55.7)$ & 0.019 \\
\hline Diabetes medications & $133(16.7)$ & $118(15.9)$ & NS & $104(13.6)$ & $206(14.2)$ & NS \\
\hline Lipid-lowering medications & $280(35.2)$ & $232(31.4)$ & NS & $122(16.0)$ & $273(18.9)$ & NS \\
\hline Alcoholic drinks/day & $\begin{array}{c}(n=435)^{*} \\
2.1 \pm 1.5\end{array}$ & $\begin{array}{c}(n=454)^{*} \\
0.9 \pm 1.0\end{array}$ & $<0.001$ & $\begin{array}{c}(n=335)^{*} \\
1.4 \pm 0.7\end{array}$ & $\begin{array}{c}(n=460)^{*} \\
0.5 \pm 0.5\end{array}$ & $<0.001$ \\
\hline $\begin{array}{l}\text { Binge drinkers } \mathrm{N} \\
\text { (\% from those who drank) }\end{array}$ & $29(6.6)$ & $4(0.8)$ & $<0.001$ & $3(0.9)$ & $4(0.8)$ & NS \\
\hline Cigarettes/day & $\begin{array}{l}(n=129)^{*} \\
7.1 \pm 15.1\end{array}$ & $\begin{array}{c}(n=255)^{*} \\
4.8 \pm 7.7\end{array}$ & NS & $\begin{array}{l}(n=104)^{*} \\
5.1 \pm 10.5\end{array}$ & $\begin{array}{c}(n=516)^{*} \\
4.3 \pm 5.6\end{array}$ & NS \\
\hline $\begin{array}{l}\text { Smoking duration }>5 \text { yrs } \\
\mathrm{N} \text { (\% from those who } \\
\text { smoked) }\end{array}$ & $\begin{array}{c}(n=503)^{*} \\
483(96.0)\end{array}$ & $\begin{array}{c}(\mathrm{n}=328)^{*} \\
307(93.6)\end{array}$ & NS & $\begin{array}{l}(\mathrm{n}=389)^{*} \\
341(87.6)\end{array}$ & $\begin{array}{c}(\mathrm{n}=428)^{*} \\
340(79.4)\end{array}$ & 0.001 \\
\hline Caffeine intake $>100 \mathrm{mg} /$ day & $85(10.7 \%)$ & $89(12.0 \%)$ & NS & $106(13.9 \%)$ & $174(12.0 \%)$ & NS \\
\hline
\end{tabular}

NS — non significant; SD — standard deviation; Differences were tested with $\mathrm{t}$ test or chi-square test; *Number of participants with available data when different from total $\mathrm{n}$

who consumed less or more than $100 \mathrm{mg}$ caffeine per day (not presented).

The logistic regression with diagnosed hypertension (based on the hypertension medication use) as dependent variable and controlling for age and sex revealed positive significant relationship with waist circumference in both cohorts (Tab. 4). Other

Table 4. Logistic regression with diagnosed hypertension (based on hypertension medications) as dependent variable and different predictors in NHANES and CroHort cohorts

\begin{tabular}{|c|c|c|}
\hline Predictors & $\begin{array}{c}\text { NHANES } \\
\text { Hypertension OR } \\
(95 \% \mathrm{CI})\end{array}$ & $\begin{array}{c}\text { CroHort } \\
\text { Hypertension OR } \\
(95 \% \mathrm{Cl})\end{array}$ \\
\hline Age & $\begin{array}{c}1.05 \\
(1.03,1.06)^{*}\end{array}$ & $\begin{array}{c}1.04 \\
(1.01,1.08)^{*}\end{array}$ \\
\hline Waist circumference & $\begin{array}{c}1.02 \\
(1.01,1.03)^{*}\end{array}$ & $\begin{array}{c}1.03 \\
(1.01,1.06)^{*}\end{array}$ \\
\hline Education & $\begin{array}{c}0.96 \\
(0.85,1.07)\end{array}$ & $\begin{array}{c}0.99 \\
(0.69,1.42)\end{array}$ \\
\hline Annual income & $\begin{array}{c}0.99 \\
(0.89,1.10)\end{array}$ & $\begin{array}{c}0.88 \\
(0.63,1.21)\end{array}$ \\
\hline Alcohol drinks/day & $\begin{array}{c}1.01 \\
(0.88,1.15)\end{array}$ & $\begin{array}{c}0.68 \\
(0.45,1.03)\end{array}$ \\
\hline Smoking index & $\begin{array}{c}1.01 \\
(0.98,1.04)\end{array}$ & $\begin{array}{c}0.98 \\
(0.94,1.02)\end{array}$ \\
\hline $\begin{array}{l}\text { Diabetes } \\
\text { medications }\end{array}$ & $\begin{array}{c}0.37 \\
(0.25,0.55)^{*}\end{array}$ & $\begin{array}{c}0.40 \\
(0.16,0.98)^{*}\end{array}$ \\
\hline $\begin{array}{l}\text { Lipid-lowering } \\
\text { medications }\end{array}$ & $\begin{array}{c}0.56 \\
(0.60,1.09)\end{array}$ & $\begin{array}{c}0.21 \\
(0.15,0.29)^{*}\end{array}$ \\
\hline
\end{tabular}

$\mathrm{OR}$ - odds ratio; $\mathrm{Cl}$ - confidence interval; ${ }^{*} \mathrm{p}<0.05$ variables, namely, income, alcohol and smoking did not reach significance in either cohort, except education (negative significance in CroHort). Interestingly, odds for having hypertension were lower in NHANES participants using diabetes medications and in CroHort participants using both diabetes and lipid-lowering medications (Tab. 4).

\section{Discussion}

Our main findings indicate that both the measured blood pressure and the prevalence of hypertension, determined either by the use of hypertension medications or by blood pressure values, were significantly higher in Croatian men and women compared to Americans. Regression analysis revealed that waist circumferences was main positive predictor and education a negative predictor of blood pressure in CroHort participants, but the significance was not reached in NHANES participants, although the trends were similar. It has been confirmed in several studies that waist circumference has a strong association with the risk of hypertension [14-16]. Waist circumference reflects abdominal fat distribution and is not significantly influenced by height [17]. Since our participants from two studies significantly differed in body mass index, we controlled the influence of body mass index in the regression analysis and consequently obtained a finding of positive impact of waist circumference on blood pressure. 
Based on the data from recent surveys, the prevalence of hypertension in the United States and in Croatia is higher compared to our CroHort and NHANES data from 2008. Recent multinational study evaluating the latest national surveys of hypertension prevalence in 12 high income countries around the world showed that the prevalence of hypertension in the United States men and women (40-79 years) was $45 \%$ and $44 \%$ respectively [5]. According to the Croatian Society for Hypertension, the 2017 prevalence of hypertension for men and women was $54.1 \%$ and $45.9 \%$ [6]. We may presume that there is a slight upward trend in the prevalence of hypertension within 10 years in both populations. The higher prevalence of hypertension based on medication use than on blood pressure values in both cohorts indicates a good regulation of blood pressure in patients with hypertension.

Our results did not show association with number of household members, household income or marital status and hypertension in either cohort. It is noticeable that the highest worldwide hypertension prevalence has shifted from high-income to low-income countries. From 2000 to 2010, the prevalence of hypertension decreased by $2.6 \%$ in high-income countries, but increased by $7.7 \%$ in low/middle-income countries [18]. The education level was significantly negatively related to blood pressure in Croatian participants, particularly women, but did not reach significance in American participants, although the trend was the same (not presented). Other studies reported lower education level presenting a higher risk of hypertension [19].

Considering alcohol consumption, most studies showed that heavy alcohol consumption increases the risk of hypertension and that reducing alcohol intake lowers blood pressure in a dose-dependent manner $[20,21]$. This association was not confirmed in our participants, probably because just a half of men and less than half of women in both cohorts drank, maintaining 1-2 drinks/day for men and even less for women. Binge drinking was low, ranging from $0.8 \%$ to $0.9 \%$, except in American men (6.6\%). Nevertheless, the American women with binge drinking had significantly higher both systolic and diastolic blood pressure, compared to non-binge drinkers (not presented). In our analysis, although the prevalence of everyday drinking was higher in CroHort compared to NHANES men, the quantity of daily alcohol intake, as well as binge drinking was lower in Croatians of both sexes.

Association between smoking and hypertension was not confirmed in either of the cohorts, probably because only a fraction of participants smoked and even those who smoked had on average less than 10 cigarettes/day. Although some epidemiological studies supported the association between smoking and hypertension $[22,23]$, most of available data did not clearly confirm a direct causal relationship between the two [24, 25]. In both cohorts the proportion of smokers was the highest among people of lower educational level and lower income (data not presented), which is in accordance with other European countries [26], indicating that the consciousness of the harmful effects of smoking increases with education, also corroborated in other studies. The awareness of bad effects of smoking on health is also higher in the United States than in Croatia [27], probably because of a long tradition of legal regulations, ban of smoking in public places and contra-advertisements.

The findings in our study that odds for having hypertension was reduced in people taking diabetes (NHANES participants) and both diabetes and lipid-lowering medications (CroHort participants) indicate that better healthcare and use of necessary medications help in overall better health outcomes, including management of blood pressure. It seems that lower awareness as well as a poorer antihypertensive therapy adherence could be the reasons of higher prevalence of hypertension in Croatia [28]. It has been confirmed that poor therapy adherence in chronic diseases remains a global problem [29, 30]. In Croatia, the study conducted among general practitioners who usually prescribe therapy for hypertension, showed that their communication skills were not specifically geared to advise their patients about better medication adherence. So, there is still no clear strategy for adherence improvement in Croatia today. The latter could possibly explain why Croatian men in this study, despite being younger and less obese than American men, still had higher blood pressure and higher prevalence of hypertension and how use of diabetes and lipid-lowering medications reduced the risk of hypertension.

\section{Limitations and strengths}

The main barrier for this project was obtaining comparable variables from the two data sets. Many variables could not be compared between two cohorts directly since they were categorized in different ways or there was a lack of standardized measures or methodologies; e.g. dietary variables, use of healthcare service, quality of life, etc. Inability to compare food intake and healthcare services between two populations posed a limit to the overall analysis. The lack of standardized prevalence for hypertension and some 
other variables was another limitation. Also, the surveys in both cohorts were done in 2007-2008, thus the prevalence of some conditions have changed; however, the overall trends remained the same and the changes in some variables, e.g. alcohol consumption and smoking are addressed in Discussion. There might have been some subjective bias in both cohorts in case of self-reported variables, like use of medications, smoking, alcohol intake, etc., which is typical for any self-reported assessment. The strengths of our analysis are inclusion of a large number of participants as well as the assessed variables from two countries with the Croatian study being one of the largest health assessments in the country and the NHANES in the United States. The Croatian participants are exposed to different environments and lifestyles, yet ethnically homogenous, thus similar to the Caucasian segment of NHANES population used in this analysis. Additionally, no study compared health related variables of Croatian population with that of the United States.

\section{Conclusions}

Prevalence of hypertension based either on medication use or blood pressure values was significantly higher in CroHort compared to the NHANES participants. Higher prevalence of hypertension diagnosed by medication use than with blood pressure values indicates a relatively good control of the disease in both populations. Waist circumference was an independent positive predictor, while the education was a negative predictor for measured blood pressure in CroHort participants; the significance was not reached in NHANES participants, although the trends were similar. Alcohol consumption smoking, coffee drinking, as well as other demographic and lifestyle characteristics examined (number of household members, income, physical activity), showed no association with blood pressure/hypertension in either cohort. The use of diabetic medications decreased the risk of hypertension in both cohorts, while the use of lipid-lowering medication additionally decreased the risk in CroHort participants, indicating that better health maintenance might decrease the odds for hypertension.

We speculate that higher mortality from cardiovascular diseases in Croatia may be attributed to high prevalence of hypertension caused most probably from lower medication adherence and health maintenance, e.g. diabetes and dyslipidemia, as important comorbidities with hypertension. However, the difference in the prevalence of hypertension in two populations cannot be explained by different prevalence of some of the risk factors examined in this analysis, except education level. Future research, including addition of other risk factors, such as nutrition and genetics, examining quality and use of healthcare services, as well as studying adherence to and compliance with treatment for chronic diseases, particularly hypertension, could provide better explanations.

\section{Funding}

None.

\section{Declaration of interest statement}

Authors have no conflicts of interest to disclose.

\section{References}

1. Global Burden of Metabolic Risk Factors for Chronic Diseases Collaboration. Cardiovascular disease, chronic kidney disease, and diabetes mortality burden of cardiometabolic risk factors from 1980 to 2010: a comparative risk assessment. Lancet Diabetes Endocrinol. 2014; 2(8): 634-647, doi: 10.1016/S22138587(14)70102-0, indexed in Pubmed: 24842598.

2. Robert L, Labat-Robert J. Longevity and aging: role of genes and of the extracellular matrix. Biogerontology. 2015; 16(1): 125-129, doi: $10.1007 / \mathrm{s} 10522-014-9544-x$, indexed in Pubmed: 25502365.

3. Bayod S, Guzmán-Brambila C, Sanchez-Roige S, et al. Voluntary exercise promotes beneficial anti-aging mechanisms in SAMP8 female brain. J Mol Neurosci. 2015; 55(2): 525-532, doi: 10.1007/ s12031-014-0376-6, indexed in Pubmed: 25027560.

4. Mazzotti DR, Guindalini C, Moraes WA, et al. Human longevity is associated with regular sleep patterns, maintenance of slow wave sleep, and favorable lipid profile. Front Aging Neurosci. 2014; 6: 134, doi: 10.3389/fnagi.2014.00134, indexed in Pubmed: 25009494.

5. NCD Risk Factor Collaboration (NCD-RisC). Long-term and recent trends in hypertension awareness, treatment, and control in 12 high-income countries: an analysis of 123 nationally representative surveys. Lancet. 2019; 394(10199): 639-651, doi: 10.1016/S0140-6736(19)31145-6, indexed in Pubmed: 31327564.

6. Milicic B, Dapic K, Domislovic V, et al. Hypertension and cardiovascular risk factors in Croatia. J Hypertens. 2018; 36(Suppl 1): e33-e34, doi: 10.1097/01.hjh.0000539044.15168.73.

7. Carter AN, Ralston PA, Young-Clark I, et al. Diabetic indicators are the strongest predictors for cardiovascular disease risk in African American adults. Am J Cardiovas Disease. 2016; 6(3): 129-137, indexed in Pubmed: 27679747.

8. The World Bank. World Bank Country and Lending Groups. Country Classification. https://datahelpdesk.worldbank.org/ knowledgebase/articles/906519-world-bank-country-andlending-groups. (September 09, 2020).

9. National Center for Health Statistics. Mortality data. https:// www.cdc.gov/nchs/nvss/deaths.htm. (September 09, 2020).

10. Croatian Institute of Public Health. Croatian Institute of Public Health. Report about dead persons in Croatia, 2008 and 2016.

11. Uhernik AI, Vuletić S, Kern J, et al. The Croatian Adult Health Cohort Study (CroHort) — background, methodology \& perspectives. Coll Antropol. 2012; 36 Suppl 1: 3-7, doi: 10.5671/ ca.2012361s.3, indexed in Pubmed: 22338740.

12. Centers for Disease Control and Prevention. NHANES, History. https://www.cdc.gov/nchs/nhanes/history (September 09, 2020). 
13. Organisation for Economic Co-operation and Development (OECED). https://data.oecd.org/hha/household-spending (September 09, 2020).

14. Levine DA, Calhoun DA, Prineas RJ, et al. Moderate waist circumference and hypertension prevalence: the REGARDS Study. Am J Hypertens. 2011; 24(4): 482-488, doi: 10.1038/ ajh.2010.258, indexed in Pubmed: 21233800.

15. Poirier $P$, Lemieux I, Mauriège $P$, et al. Impact of waist circumference on the relationship between blood pressure and insulin: the Quebec Health Survey. Hypertension. 2005; 45(3): 363-367, doi: 10.1161/01.HYP.0000155463.90018.dc, indexed in Pubmed: 15668356.

16. Siani A, Cappuccio FP, Barba G, et al. The relationship of waist circumference to blood pressure: the Olivetti Heart Study. Am J Hypertens. 2002; 15(9): 780-786, doi: 10.1016/s08957061(02)02976-x, indexed in Pubmed: 12219872.

17. Lean MEJ, Han TS, Seidell JC. Impairment of health and quality of life in people with large waist circumference. BMJ. 1998; 351(9106): 853-856, doi: 10.1016/s0140-6736(97)10004-6, indexed in Pubmed: 9525361.

18. Bloch MJ. Worldwide prevalence of hypertension exceeds 1.3 billion. J Am Soc Hypertens. 2016; 10(10): 753-754, doi: 10.1016/j.jash.2016.08.006, indexed in Pubmed: 27660007.

19. Gharipour M, Khosravi A, Sadeghi M, et al. Socioeconomic characteristics and controlled hypertension: Evidence from Isfahan Healthy Heart Program. ARYA Atheroscler. 2013; 9(1): 77-81, indexed in Pubmed: 23696763.

20. Roerecke M, Tobe SW, Kaczorowski J, et al. Sex-Specific Associations Between Alcohol Consumption and Incidence of Hypertension: A Systematic Review and Meta-Analysis of Cohort Studies. J Am Heart Assoc. 2018; 7(13), doi: 10.1161/JAHA.117.008202, indexed in Pubmed: 29950485.

21. Roth I, Casas R, Ribó-Coll M, et al. Consumption of Aged White Wine under a Veil of Flor Reduces Blood Pressure-Increasing Plasma Nitric Oxide in Men at High Cardiovascular Risk.
Nutrients. 2019; 11(6), doi: 10.3390/nu11061266, indexed in Pubmed: 31167421.

22. Dikalov S, Itani H, Richmond B, et al. Tobacco smoking induces cardiovascular mitochondrial oxidative stress, promotes endothelial dysfunction, and enhances hypertension. Am J Physiol Heart Circ Physiol. 2019; 316(3): H639-H646, doi: 10.1152/ ajpheart.00595.2018, indexed in Pubmed: 30608177.

23. Niskanen L, Laaksonen DE, Nyyssönen K, et al. Inflammation, abdominal obesity, and smoking as predictors of hypertension. Hypertension. 2004; 44(6): 859-865, doi: 10.1161/01. HYP.0000146691.51307.84, indexed in Pubmed: 15492131.

24. Primatesta P, Falaschetti E, Gupta S, et al. Association between smoking and blood pressure: evidence from the health survey for England. Hypertension. 2001; 37(2): 187-193, doi: 10.1161/01. hyp.37.2.187, indexed in Pubmed: 11230269.

25. Virdis A, Giannarelli C, Fritsch Neves M, et al. Cigarette smoking and hypertension. Curr Pharm Des. 2010; 16(23): 2518-2125, doi: 10.1161/01.hyp.37.2.187.

26. EUROStat. Tobacco consumption statistics. https://ec.europa. eu/eurostat/web/products-datasets/-/sdg_03_30 (September 09, 2020)

27. Dečković-Vukres V V, Ivičević Uhernik A, Mihel S. Survey on the use of tobacco in the adult Croatian population. Croatian Institute of Public Health, Zagreb 2015.

28. Gongola A, Tanta I, Sviličić N. The attitudes of general practitioners in Croatia toward interpersonal communication and adherence. Coll Antropol. 2019; 43(1): 69-78.

29. Napolitano F, Napolitano P, Angelillo IF, et al. Collaborative Working Group. Medication adherence among patients with chronic conditions in Italy. Eur J Public Health. 2016; 26(1): 48 52, doi: 10.1093/eurpub/ckv147, indexed in Pubmed: 26268628.

30. Vrijens B, Antoniou S, Burnier M, et al. Current Situation of Medication Adherence in Hypertension. Front Pharmacol. 2017; 8: 100, doi: 10.3389/fphar.2017.00100, indexed in Pubmed: 28298894. 